Original article

\title{
Performance of rapid test in detection of HBsAg in frozen sera
}

\author{
Firat Zafer Mengeloglu, Seyda Karabörk, Esra Kocoglu, Tekin Tas, Özlem Bucak
}

Department of Medical Microbiology, Abant Izzet Baysal University School of Medicine, Bolu, Turkey

Received 12 July 2013, Accepted 1 September 2013

(C) 2013, Mengeloglu F.Z., Karabörk S., Kocoglu E., Tas T., Bucak O.

(C) 2013, Russian Open Medical Journal

\begin{abstract}
Background - Hepatitis B is a widespread infectious disease throughout the world. Clinical and laboratory diagnosis of this infection is important. Rapid test of hepatitis B, known as cassette test, is a useful test that is easy to perform as well as it may have lack of sensitivity and specificity. Materials and Methods - Sera of a total of 55 patients were used for the study. All the sera that were tested for hepatitis B surface antigen ( $\mathrm{HBsAg}$ ) using macro enzyme-linked immunosorbent assay (Macro ELISA) were stored at $-20^{\circ} \mathrm{C}$ for a maximum period of 3.5 years. The sera were thawed and tested again for HBsAg using the Nanosign rapid test kit (Bioland, South Korea) for hepatitis $B$ virus (HBV) infection. Results - A total of $16(29.1 \%)$ sera revealed negative and the rest 39 were positive, meaning of a positivity rate of $70.9 \%$. Rapid test revealed a very low positivity rate of $6.6 \%$ in sera with below $100 \mathrm{IU} / \mathrm{ml}$ level of $\mathrm{HBsAg}$. In contrast, only two of the rest 40 sera with HBsAg levels above 100 units were negative, meaning of a positivity rate of $95.0 \%$ in high HBsAg level samples. A highly significant positive correlation was found between positivity levels and HBsAg levels $(R=0.734, P<0.001$, correlation is significant at the 0.01 level by 2-tailed analysis). We didn't find any correlation between positivity and the period passed after freezing. Besides this, no significant difference was observed amongst the groups in terms of the time intervals of freezing. These findings suggest that the time passed after the first freeze of the sera didn't cause any impact on the results of rapid tests. Conclusion - The findings of the present study suggest that the rapid test of HBV infection is reliable in sera with high levels of HBsAg, and the time passed after freezing of the sample doesn't change the results of the tests. Besides this, a negative rapid test result doesn't rule out the infection.
\end{abstract}

Keywords: rapid test, $\mathrm{HBsAg}$, frozen sera, HBV

Cite as Mengeloglu FZ, Karabörk S, Kocoglu E, Tas T, Bucak O. Performance of Rapid Test in Detection of HBsAg in Frozen Sera. Russian Open Medical Journal 2014; 3: 0103.

Correspondence to Firat Zafer Mengeloglu. Department of Medical Microbiology, Abant Izzet Baysal University Medical School, 14280 Gölköy, Bolu, Turkey. E-mail : mengeloglu@gmail.com. Phone : +905336404908. Fax : +903742534615.

\section{Introduction}

Hepatitis B is a widespread infectious disease throughout the world. Clinical and laboratory diagnosis of this infection is important. Serologic testing for hepatitis B surface antigen (HBsAg) is the primary way to identify patients with hepatitis B virus (HBV) infection [1]. Testing has been recommended particularly for pregnant women, infants born to HBsAg-positive mothers, sex partners and household contacts of HBV-infected persons, persons born in countries with high $\mathrm{HBsAg}$ prevalence, persons who are the source of blood and persons infected with human immunodeficiency virus $[1,2]$.

Rapid test of hepatitis B, known as cassette test, is a useful test that is easy to to perform as well as it may have lack of sensitivity and specificity. Rapid test detects $\mathrm{HBsAg}$ in serum. In many smallsized laboratories, the rapid test has still been used in the diagnosis of HBV infection. In addition, it is used in blood transfusion units in cases of emergencies when the emergent need for blood is occured for severe injured patients [1-3].

Sera of the patients have been stored in freezers for long times for many reasons such as repeating tests, hanging on for further or additional tests, or for some judicial occasions. The time passed in the freezer for the sera may be important in some tests in terms of the probable desrease in sensitivity. It is crucial for some cases to know whether the test is reliable in sera freezed for many years $[1,2,4]$.

In the present study, it was aimed to investigate whether the rapid test of HBV infection can still reveal accurate results in HBsAg-positive sera freezed for some years.

The aim: In the present study, it was aimed to investigate whether the rapid test of HBV infection can still reveal accurate results in $\mathrm{HBsAg}$-positive sera freezed for some years.

\section{Material and Methods \\ Rapid tests}

Sera of a total of 55 patients were used for the study. All the sera that were tested for HBsAg using macro enzyme-linked immunosorbent assay (Macro ELISA) were stored at $-20^{\circ} \mathrm{C}$ for a maximum period of 3.5 years. The sera were thawed and tested again for HBsAg using the Nanosign rapid test kit (Bioland, South Korea) for HBV infection. The tests were performed following the recommendations of the manufacturer. The test results were scored ranging from negative to "++++" including gray zone. The sera were groupped according to the periods passed after the first freeze of them. 
Table 1. Distribution of means \pm standard deviations and number of sera according to levels of $\mathrm{HBsAg}$ and positivity of rapid tests

\begin{tabular}{lcccccc}
\hline \multirow{2}{*}{$\begin{array}{c}\text { Test } \\
\text { result }\end{array}$} & $n$ & \multirow{2}{*}{$\mathrm{N} \pm \mathrm{SD}$} & \multicolumn{4}{c}{ HBsAg level (S/CO) } \\
\cline { 4 - 7 } & & & $\begin{array}{c}1.0- \\
4.9\end{array}$ & $\begin{array}{c}5.0- \\
99.9\end{array}$ & $\begin{array}{c}100- \\
999\end{array}$ & \multirow{2}{*}{ 1000 } \\
\hline Negative & 16 & $96.44 \pm 297.36$ & 7 & 7 & 1 & 1 \\
Gray zone & 3 & $1247.67 \pm 572.38$ & 0 & 0 & 1 & 2 \\
+ & 10 & $2435.30 \pm 1800.01$ & 0 & 1 & 1 & 8 \\
++ & 11 & $3632.00 \pm 1560.15$ & 0 & 0 & 1 & 10 \\
+++ & 10 & $2737.40 \pm 1154.97$ & 0 & 0 & 0 & 10 \\
++++ & 5 & $3709.60 \pm 1564.13$ & 0 & 0 & 0 & 5 \\
\hline Total & 55 & $2100.24 \pm 1864.10$ & 7 & 8 & 4 & 36 \\
\hline
\end{tabular}

Table 2. Distribution of numbers of sera according to positivity levels of rapid test and time passed after freezing of sera

\begin{tabular}{|c|c|c|c|c|c|}
\hline \multirow{2}{*}{ Test result } & \multirow{2}{*}{$n$} & \multicolumn{4}{|c|}{ Tima passed in the storage } \\
\hline & & $<1$ year & $1-2$ years & $2-3$ years & $>3$ years \\
\hline Negative & 16 & 3 & 3 & 8 & 2 \\
\hline Gray zone & 3 & 1 & 0 & 2 & 0 \\
\hline+ & 10 & 2 & 3 & 4 & 1 \\
\hline++ & 11 & 2 & 3 & 2 & 4 \\
\hline+++ & 10 & 3 & 3 & 1 & 3 \\
\hline++++ & 5 & 3 & 1 & 1. & 0 \\
\hline Total & 55 & 14 & 13 & 18 & 10 \\
\hline
\end{tabular}

\section{ROC Curve}

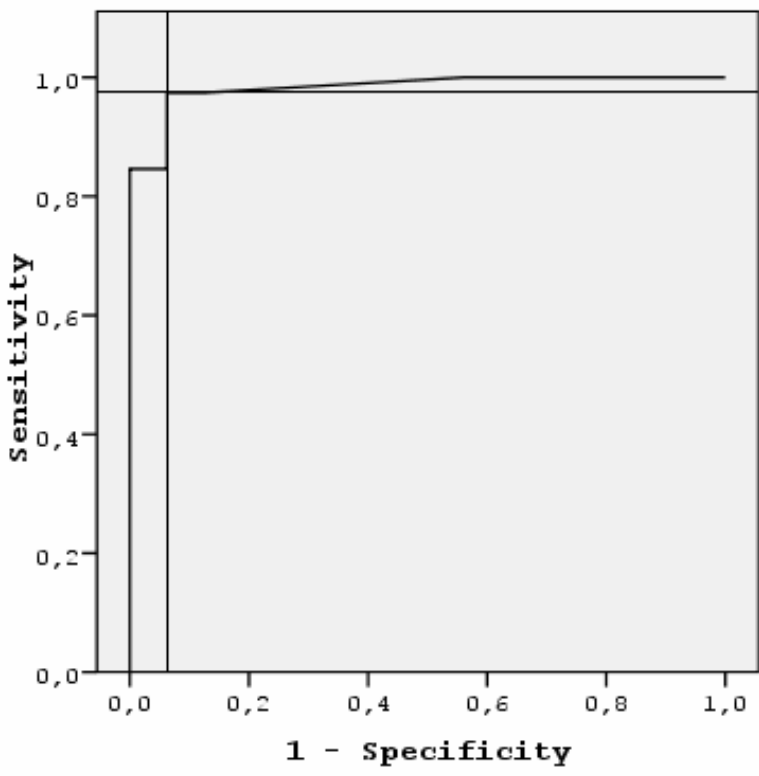

Diagonal segments are produced by ties.

Figure 1. An HBsAg level of $\mathbf{4 0 5 . 5 0}$ or more had a sensitivity of $\mathbf{9 7 . 4 \%}$ specificity of $93.7 \%$; positive predictive value of $97.4 \%$; negative predictive value of $93.7 \%$; and accuracy of $96.4 \%$ (AUC: $0.983, p<0.001$; LB: 0.956 UB: 1.011)

\section{Statistical analysis}

Statistical analysis was performed using SPSS 15.0 software (IBM SPSS Inc., Chicago, IL, USA). Whether the continuous variables were normally distributed was assessed using the Shapiro-Wilk test. The Levene test was used to evaluate the homogeneity of variances. Spearman's rank correlation test was used for correlation and relation between indicated parameters. Values were presented as mean \pm standard deviations $(\mathrm{M} \pm \mathrm{SD})$. Group means were compared by one-way analysis of variance (ANOVA). The Kruskal-Wallis test was used to compare median values. The Wilcoxon signed-rank test was used for intra-group comparisons. $\mathrm{p}<0.05$ was considered to indicate statistical significance.

\section{Results}

A total of $16(29.1 \%)$ sera revealed negative and the rest 39 were positive, meaning of a positivity rate of $70.9 \%$. All of seven sera that had HBsAg level between 1-4.9 S/CO with macro ELISA were negative, and one of eight sera with $\mathrm{HBsAg}$ levels between 5$99.9 \mathrm{~S} / \mathrm{CO}$ was positive using the rapid test (Table 1). According to these findings, rapid test revealed a very low positivity rate of $6.6 \%$ in sera with below $100 \mathrm{~S} / \mathrm{CO}$ level of $\mathrm{HBsAg}$. In contrast, only two of the rest 40 sera with HBsAg levels above $100 \mathrm{~S} / \mathrm{CO}$ were negative, meaning of a positivity rate of $95.0 \%$ in high $\mathrm{HBsAg}$ level samples.

A highly significant positive correlation was found between positivity levels and HBsAg levels $(R=0.734, p<0.001$, correlation is significant at the 0.01 level by 2-tailed analysis). In ROC analysis, we found that an HBsAg level of 405.50 or more had a sensitivity of $97.4 \%$; specificity of $93.7 \%$; positive predictive value of $97.4 \%$; negative predictive value of $93.7 \%$; and accuracy of $96.4 \%$ (AUC: 0.983, p<0.001; LB: 0.956 UB: 1.011 ) (Figure 1).

We didn't find any correlation between positivity and the period passed after freezing (Table 2). Besides this, no significant difference was observed amongst the groups in terms of the time intervals of freezing. These findings suggest that the time passed after the first freeze of the sera didn't cause any impact on the results of rapid tests.

\section{Discussion}

Testing for HBV infection meets established public health screening criteria [1]. Screening is a basic health tool used to identify unrecognized health conditions so treatment can be offered before symptoms occur and, so interventions can be implemented to reduce the continued transmission [1]. Rapid diagnosis of HBV infection is emergent in some exceptional cases. Besides this, importance of specificity, accuracy, and reproducibility of the test results is incontrovertible. It has been an important issue whether the time passed after the freezing of the clinical samples has a negative effect on the accuracy of the test results in diagnosis of hepatitis $B$.

In the present study, it was shown that the time passed after the freezing didn't change the test results using the rapid test. The time used in this study ranged from weeks to 3.5 years. The sera with higher HBsAg levels revealed positive results as well as the ones with lower levels did negative without any differences in terms of the time passed. The only determinant effecting the results was the initial HBsAg level detected using macro ELISA method. According to these findings, we can consider that rapid test can diagnose the HBV infection in the sera with high level of $\mathrm{HBsAg}$, and we can not rule out the infection if the result of the rapid test kit reveals negative. Our findings suggest that the result don't change with the time passed after freezing of the sample.

The positivity levels of the rapid test were found to be positively correlated with HBsAg levels of the sera used. The positivity levels even didn't differ with the time of freezing. These findings suggest that positive results of the rapid test is reliable as well as a high positive result is likely to mean a high HBsAg level. 
Cha et al. [5] found the sensitivities of three rapid antigene kits for HBsAg between $65 \%$ and $85 \%$. Bottero et al. [6] found that three rapid test kits detecting $\mathrm{HBsAg}$ had sensitivities between $90.5 \%$ and $96.5 \%$, and had a specificity between $99.5 \%$ and $99.8 \%$. Their results revealed high specificity percentages but low sensitivity rates. They considered that the false-negative results were due to inactive $\mathrm{HBsAg}$ carriers. Our findings seem to be similar to their data, and our false negative test results can also be due to the inactive carriers who may have low HBsAg levels [7]. In addition, genotyping studies reported that the genetic diversity of HBV was high in all over the world, and hence the analytical sensitivity of the assays detecting HBsAg might be dependent on HBV genotype or subtype, or some mutations, and so could possibly lead to false negative results [8-10]. In the present study, we didn't perform any molecular tests for the distribution of HBV genotypes of the sera we used, so we are not sure about the reason of the low sensitivity concerning the genetical differences.

Our ROC curve analysis revealed that an HBsAg level of 405.50 $\mathrm{S} / \mathrm{CO}$ showed very high sensitivity and specificity rates for rapid test. However, the value of $405.50 \mathrm{~S} / \mathrm{CO}$ is so far away from critical detection breakpoint for the disease. This analysis support the low sensitivity of the rapid test in low antigene level in frozen sera.

Rapid HBV tests for HBsAg are not widely recommended for use even in blood transfusion centers due to their lower sensitivities [8]. A meta-analysis by Hwang et al. [11] evaluated a total of 38 studies at this topic concludes their collected data as these tests could be useful in small-sized laboratories and for epidemiological studies.

Bienek et al. [12] compared the effects of storage conditions of sera on the test results of HBV, HCV and HIV infections. They concluded that the diagnostic performance of the tests vary among products and storage conditions. In addition, Lau et al. [4] reported similar sensitivity and specificity rates between samples such as frozen sera, fresh sera and fresh blood. In our study, the storage conditions of the sera were all the same in terms of temperature and humidity.

Though the rapid test couldn't catch the low-HBsAg-level sera, absence of HBsAg doesn't rule out the HBV infection due to the phase of the disease such as window period. Because presence or absence of HBsAg doesn't determine the period of the infection, it has to be evaluated with other hepatitis $B$ markers such as anti$\mathrm{HBSAb}$, anti-HBc IgM and total, $\mathrm{HBeAg}$, and anti-HBeAb, and HBV DNA load [1-3].

\section{Conclusion}

The findings of the present study suggest that the rapid test of $\mathrm{HBV}$ infection is reliable in sera with high levels of $\mathrm{HBsAg}$, and the time passed after freezing of the sample doesn't change the results of the tests. Besides this, a negative rapid test result doesn't rule out the infection.

\section{Acknowledgement}

This study was supported by Viral Hepatitis Prevention Society.

Conflict of interest: none to declare.

\section{References}

1. Weinbaum CM, Williams I, Mast EE, Wang SA, Finelli L, Wasley A, et al. Recommendations for identification and public health management of persons with chronic hepatitis B virus infection. MMWR Recomm Rep 2008; 57(RR-8): 1-20.

2. Randrianirina F, Carod JF, Ratsima E, Chrétien JB, Richard V, Talarmin A. Evaluation of the performance of four rapid tests for detection of hepatitis B surface antigen in Antananarivo, Madagascar. J Viro Methods 2008; 151(2): 294-297. (doi: 10.1016/j.jviromet.2008.03.019) (PMID: 18462816)

3. Lin YH, Wang Y, Loua A, Day GJ, Qiu Y, Nadala EC Jr, Allain JP, Lee HH Evaluation of a new hepatitis $B$ virus surface antigen rapid test with improved sensitivity. J Clin Microbiol 2008; 46(10): 3319-3324. (doi: 10.1128/JCM.00498-08) (PMID: 18701669) (PMCID: PMC2566085)

4. Lau DT, Ma H, Lemon SM, Doo E, Ghany MG, Miskovsky E, Woods GL, Park $\mathrm{Y}$, Hoofnagle JH. A rapid immunochromatographic assay for hepatitis B virus screening. J Viral Hepat 2003; 10(4): 331-334. (PMID: 12823602) (doi: 10.1046/j.1365-2893.2003.00418.x)

5. Cha YJ, Kum DG, Kim SW, Kim TY, Kim JR, Kim HS, et al. Annual report on external quality assessment in immunoserology in Korea (2002). J Lab Med \& Quality Assurance 2003; 25: 51-72.

6. Bottero J, Boyd A, Gozlan J, Lemoine M, Carrat F, Collignon A, et al. Performance of rapid tests for detection of HBsAg and anti-HBsAb in a large cohort, France. J Hepatol 2013; 58(3): 473-478. (doi: 10.1016/j.jhep.2012.11.016) (PMID: 23183527)

7. Brunetto $M R$, Oliveri $F$, Colombatto $P$, Moriconi F, Ciccorossi $P$, Coco $B$ et al. Hepatitis $B$ surface antigen serum levels help to distinguish active from inactive hepatitis B virus genotype D carriers. Gastroenterology 2010; 139(2): 483-490. (doi: 10.1053/j.gastro.2010.04.052) (PMID: 20451520)

8. Avellón A, Echevarría JM, Weber B, Weik M, Schobel U, Willems WR, Gerlich WH. European collaborative evaluation of the Enzygnost $\mathrm{HBsAg}$ 6.0 assay: performance on hepatitis $B$ virus surface antigen variants. $J$ Med Virol 2011; 83(1): 95-100. (PMID: 21108344)

9. Tian $Y, X u Y$, Zhang Z, Meng Z, Qin L, Lu M, Yang D. The amino Acid residues at positions 120 to 123 are crucial for the antigenicity of hepatitis B surface antigen. J Clin Microbiol 2007; 45(9): 2971-2978. (PMID: 17609325) (PMCID: PMC2045265)

10. Weber $B$. Diagnostic impact of the genetic variability of the hepatitis $B$ virus surface antigen gene. J Med Virol 2006; 78 (Suppl 1): S59-S65. (PMID: 16622880)

11. Hwang $\mathrm{SH}$, Oh HB, Choi SE, Kim HH, Chang CL, Lee EY, Son HC. Metaanalysis for the pooled sensitivity and specificity of hepatitis $B$ surface antigen rapid tests. Korean J Lab Med 2008; 28(2): 160-168. (doi: 10.3343/kjlm.2008.28.2.160) (PMID: 18458514) [Article in Korean]

12. Bienek DR, Charlton DG. The effect of simulated field storage conditions on the accuracy of rapid user-friendly blood pathogen detection kits. Mil Med 2012; 177(5): 583-588. (PMID: 22645886)

\section{Authors:}

Firat Z. Mengeloglu - Assistant Professor, Department of Medical Microbiology, Abant Izzet Baysal University School of Medicine, Bolu, Turkey;

Seyda Karabörk - Specialist, Department of Medical Microbiology, Abant Izzet Baysal University School of Medicine, Bolu, Turkey;

Esra Kocoglu - Associate Professor, Head of Medical Microbiology Department, Department of Medical Microbiology, Abant Izzet Baysal University School of Medicine, Bolu, Turkey;

Tekin Tas - Associate Professor, Department of Medical Microbiology, Abant Izzet Baysal University School of Medicine, Bolu, Turkey;

Özlem Bucak - Research Assistant, Department of Medical Microbiology, Abant Izzet Baysal University School of Medicine, Bolu, Turkey. 